\title{
PERAN BAHASA ARAB DALAM PENDIDIKAN ISLAM SEBAGAI URGENSITAS MENGHADAPI REVOLUSI INDUSTRI 4.0
}

\author{
Cahya Edi Setyawan ${ }^{1}$, Khairul Anwar ${ }^{2}$ \\ ${ }^{1}$ Sekolah Tinggi Agama Islam Masjid Syuhada \\ ${ }^{2}$ Universitas Ibrahimy Situbondo \\ cahya.edi24@gmail.com, ${ }^{2}$ mas_anwar78@yahoo.co.id
}

\begin{abstract}
With the presence of the Industrial Revolution 4.0, it automatically influenced the process of scientific development in Islamic education and Arabic. the development is felt in the aspects of its objectives, teaching methodology, and learning media, and competency standards of graduates who have soft skills and hard skills. Arabic, which has always been considered less important for some learners, has become an "Urgent" thing at the moment, namely as a door to enter the Islamic education space. The following will be explained about the influence of industrial revolution 4.0 in Islamic education and the aspects that become Urgency in Arabic as the entrance to the entry of Islamic education.
\end{abstract}

Keyword: Industrial Revolution 4.0, Islamic Education, Urgency of Arabic Language

\section{PENDAHULUAN}

Bahasa Arab berkembang seiring dengan perkembangan islam. Bahasa Arab dan pendidikan Islam bagaikan rumah dan pintunya, bahasa Arab sebagai pintunya, pendidikan islam adalah rumahnya. Rumah tidak berpintu sungguh tidak menarik dan mustahil manusia bisa memasuki rumah itu. Begitu pula, pintu berdiri sendiri tidak mungkin karena pintu bagian atau organ dari rumah. Pintu adalah hiasan yang menarik bagi sebuah rumah. Rumah yang bagus memiliki pintu yang bagus. Karena sebagai hiasan maka pintu dibuat seindah mungkin, begitu pula bahasa Arab sebagai pintu pendidikan Islam dipelajari sebaik mungkin dan sedalam mungkin agar mampu memasuki ruang keilmuan dalam pendidikan dengan pemahaman yang baik dan benar.

Titik awal kejayaan perkembangan bahasa Arab, dimulai sejak penurunan alQuran berbahasa Arab yang merupakan mukjizat yang paling agung didunia ini. Oleh karena itu, bahasa Arab secara tidak langsung berperan menjadi alat komunikasi seluruh umat Islam didunia. Hadis Rasul SAW juga dikodifikasikan berbahasa Arab. Ilmu-ilmu Keislaman di awal perkembangannya ditulis dengan bahasa Arab, dakwah-dakwah penyebaran Islam di seluruh wilayah dunia juga menggunakan bahasa Arab.

Memahami ajaran Islam tidak bisa terlepas dari pengetahuan bahasa Arab. sebab sumber-sumber primer pengetahuan Islam adalah berbahasa Arab. Umar bin Khattab r.a berkata:

"tamaklah kalian dalam mempelajari bahasa Arab karena bahasa Arab itu adalah bagian dari Agamamu"

Berdasarkan hal inilah maka orang yang hendak memahami dan mengajarkan ajaran Agama Islam dengan baik haruslah berusaha mempelajari bahasa Arab. Bahasa-bahasa selain bahasa Arab tidaklah dapat diandalkan untuk memberikan kepastian arti yang tersurat dan tersirat dari makna yang terkandung dalam Al-Quran. ${ }^{1}$

Bahasa Arab yang tertuang di dalam AlQuran menjadikannya bahasa yang sangat istimewa dan memiliki karakteristik yang berbeda dibandingkan dengan bahasa lainnya. Sejak bahasa Arab dituangkan dalam AlQuran dan di suarakan hingga saat ini, semua pengamat Barat (Orientalis) maupun Timur (Oxidentalis) menganggapnya sebagai bahasa

1 M. Akawi Jad, 1987, Al-Muhasah alYaumiyyah bi al-Lugah al-Arabiyyah, Mesir, Daar alMa'arif, h. 02 
yang memiliki standar ketinggian dan keelokan linguistik yang tertinggi. Hal ini tentu saja berdampak pada munculnya superioritas sastra dan filsafat bahkan berdampak pula pada sains seperti matematika, kedokteran, ilmu bumi dan tata bahasa Arab sendiri pada masa-masa kejayaan Islam setelahnya. ${ }^{2}$ Konsekuensi logis dari dampak tersebut menjadikan pengetahuan bahasa Arab memegang peranan yang sangat penting untuk memahami ilmu pengetahuan, lebih-lebih pengetahuan agama guna kemudian di ajarkan untuk umat.

Sebelum abad tujuh masehi, bahasa Arab adalah "bahasa statis" dan dibatasi oleh ragamnya kesukuan. Makanya, bahasa Arab saat pada saat itu dianggap bahasa yang biasa. Perubahan datang ketika Islam berkembang pesat di luar semenanjung Arabia, bahkan hingga benua yang berbeda. Dan semua berbondong-bondong masuk islam menjadikannya way of life.

Pada era milenial ini, bahasa Arab dipelajari dimana-mana dengan berbagai bentuknya baik itu diajarkan sekolah formal maupun informal. Di sektor formal bahasa Arab diajarkan di sekolah-sekolah milik pemerintah baik umum maupun keagamaan, sekolah-sekolah islam swasta milik organisasi, dan di pondok-pondok pesantren. Di pondok-pondok pesantren bahasa Arab diajarkan dengan karakteristiknya masingmasing, sebagai contoh di pondok Lirboyo Kediri, Tebu ireng Jombang bahasa Arab diajarkan dengan bentuk ilmu alat yaitu memposisikan bahasa sebagai ilmu alat untuk mempelajari ajaran Agama Islam (Nahwu dan Sharaf). Dipondok-pondok pesantren modern (Gontor, Darul Qolam, dsb) bahasa Arab diajarkan sebagai alat komunikasi dan alat diplomasi (Muhadatzah, maharah kalam, pidato, bahasa umroh dan haji dsb).

Seiring dengan perkembangan revolusi industri 4.0, dalam sebuah pembelajaran maka mengacu kepada pemanfaatan dan pengembangan media pembelajaran berbasis tegnologi yang lebih efektif dan efisien. Menjawab problem dalam pendidikan islam,

2 Hasbi Ash Shiddieqy, 1975, Falsafah Hukum Islam, Jakarta, Bulan Bintang, h. 217 dimana bahasa Arab sebagai pintu masuk keilmuan pendidikan islam maka perlu di pelajari dengan media seefektif mungkin dan semudah mungkin guna menciptakan "hasrat" pembelajar untuk mendalami bahasa Arab. Jika pembelajar menguasai bahasa Arab dengan baik, maka untuk mendalami keilmuan dalam pendidikan Islam menjadi lebih mudah. Dari paparan diatas, Penulis ingin membahas hal-hal yang berkaitan dengan urgensi bahasa arab dalam pendidikan Islam di era revolusi industri 4.0. Industri 4.0 saat ini telah melanda manusia. Dengan adanya industry 4.0, seharusnya dapat mewujudkan tujuan pendidikan Islam yang sebenarnya, yakni meningkatkan kualitas iman dan ketaqwaan untuk membentuk kepribadian muslim yang baik.

\section{METODE PENELITIAN}

Penelitian ini berbentuk penelitian kepustakaan atau disebut Library Research. Pendekatan yang digunakan adalah deskriptif analisis. Metode pengumpulan datanya menggunakan metode eksplorasi dokumendokumen atau dokumentasi. Sumber datanya berupa buku, makalah, jurnal, dan sebagainya. Setelah melihat sumber-sumber sebagai bahan data, penulis kemudian menganalisis, mensintesis dan mengantitesis hasil penemuan data.

\section{PEMBAHASAN}

\section{A. Konsep Pendidikan Islam di Era 4.0}

Dikalangan tokoh pendikan Islam ada tiga terminology yang umum digunakan dalam pendidikan Islam yaitu at-Tarbiyah (pengetahuan tentang al-Rabb), al-Ta'lim (ilmu teoritik kreativitas, komitmen tinggi dalam mengembangkan ilmu, serta sikap hidup yang menjunjung tinggi nilai-nilai ilmiah), at-Ta'dib (integrasi ilmu dan iman yang membuahkan amal). Kata Tarbiyah berasal dari kata dasar "rabba", "yurabbi" menjadi "tabiyah" yang mengandung arti memelihara, membesarkan, dan mendidik. Dalam bentuk kata kerja, kata ini dapat dijumpai di dalam Al-Quran seperti pada Surat Asy-Syu'ara ayat 18 dan al-Isra' ayat 24, yang artinya: 
"Berkata (Firaun): Bukanlah kami telah mengasuh (mendidikmu) dalam keluarga kami semenjak kamu kecil dan menghabiskan beberapa tahun dari umurmu? (Q.S. As-Syu'ara: 18)"

"...Ya Tuhan kasihanilah keduanya (orangtua) sebagaimana keduanya telah mendidikku semenjak aku kecil (Q.S. AlIsra': 24)

Istilah Ta'lim secara Etimologi berkonotasi pembelajaran, yaitu semacam proses transfer ilmu pengetahuan. Hakekat ilmu pengetahuan bersumber dari Allah SWT. Adapun proses pembelajaran (ta'lim) secara simbolis dinyatakan dalam informasi AlQur'an ketika penciptaan Adam A.S oleh Allah SWT, ia menerima pemahaman tentang konsep ilmu pengetahuan langsung dari penciptanya. Proses pembelajaran ini disajikan dengan menggunakan konsep ta'lim yang sekaligus menjelaskan hubungan antara pengetahuan Adam A.S dengan tuhannya.

Istilah Ta'dib menurut Al-Attas, adalah pengenalan dan pengetahuan secara berangsur-angsur ditanamkan ke dalam diri manusai (peserta didik) tentang tempattempat yang tepat dari segala sesuatu di dalam tatanan penciptaan. Dengan pendekatan ini pendidikan akan berfungsi sebagai pembimbing kea rah pengenalan dan pengakuan tempat Tuhan yang tepat dalam tatanan wujud dan kepribadiannya. Dalam Hadist Nabi yang artinya:

"tuhan tela mendidik, maka ia sempurnakan pendidikanku” (HR. AlAskary dari Ali r.a"

Al-Syaibany mengemukakan bahwa pendidikan islam adalah proses mengubah tingkah laku individu peserta didik pada kehidupan pribadi, masyarakat dan alam sekitarnya. Muhammad Fadhil al-Jamaly mendefenisikan pendidikan Islam sebagai upaya pengembangan, mendorong serta mengajak peserta didik hidup lebih dinamis dengan berdasarkan nilai-nilai yang tinggi dan kehidupan yang mulia. ${ }^{3}$ Dari beberapa pengertian dan ketiga Terminologi diatas dapat disimpulkan bahwa pendidikan Islam

${ }^{3}$ M. Fadhil al-Jamaly, dalam Bukhari Umar, 2011, Ilmu Pendidikan Islam, PT. Bumi Aksara, Jakarta, h. 53 memiliki empat sasaran, yaitu: a) menjaga dan memelihara fitrah anak menjelang dewasa (baligh), b) mengembangkan seluruh potensi, c) mengarahkan seluruh fitrah dan potensi menuju kesempurnaan, d) melaksanakan secara bertahap.

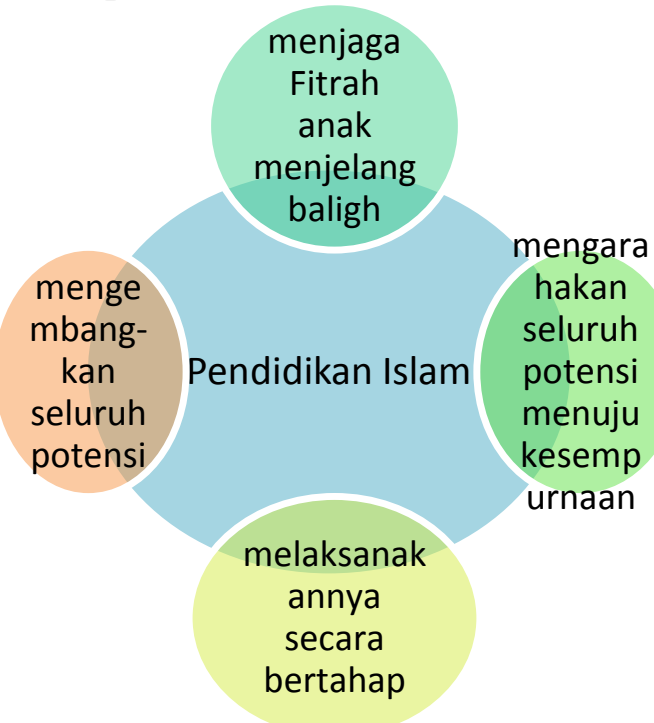

Pendidikan Islam secara umum adalah upaya sistematis untuk membantu anak didik agar tumbuh berkembang melalui aktualisasi potensi diri berdasarkan kaidah-kaidah moral Al-Quran, ilmu pengetahuan dan ketrampilan hidup (Life-skill). Akan tetapi, walaupun telah dilakukan usaha-usaah pembaharuan pendidikan Islam, namun seharusnya ditempatkan sebagai sumber otentik pengembangan pemikiran teoritis ataupun praktis bagi dasar, tujuan, proses maupun rumusan panduan atau petunjuk dalam pendidikan. Namun saat ini umat Islam belum optimal dalam pengembangan pendidikan. Pendidikan Islam mulai dilaksanakan Rasulullah setelah mendapat perintah dari Allah agar beliau menyeru kepada Allah, sebagaimana termaktub dalam Al-Quran surat Al-Mudatsir (74) ayat 1-7. Menyeru berarti mengajak, mengajak berarti membimbing, membimbing berarti mengarahkan, mengarahkan berarti mendidik.

Gambar dibawah ini tentang alur Pendidikan Islam dalam Surat Al-Mudatsir.

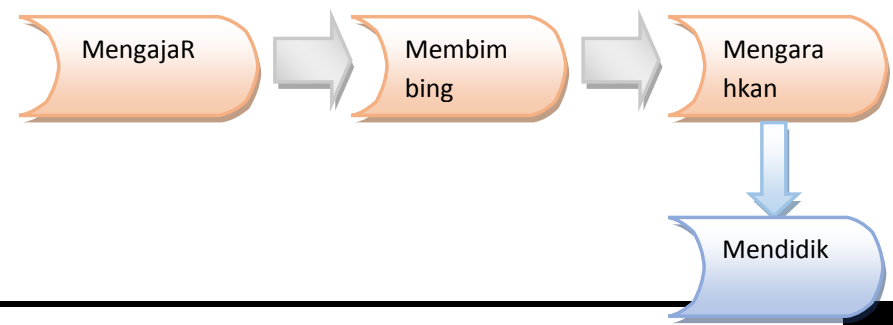


kesanggupan untuk mengkaji ilmu sekedar sebagai ilmu, 5) Mempersiapkan para pelajar

Pembahasan diatas dapat penulis simpulkan bahwa pendidikan islam merupakan sistem yang memungkinkan individu untuk mengarahkan kehidupannya sesuai dengan ideologi selama hidup di dunia. Pendidikan islam merupakan kegiatan yang sengaja dilakukan untuk membimbing dan mengarahkan seseorang menuju terbentuknya insan kamil berdasarkan nilai islam dengan tetap memelihara hubungan nya dengan sang pencipta, diri sendiri, alam semesta dan sesamanya.

\section{B. Arah Tujuan Pendidikan Islam}

Ibnu Khaldun mengatakan bahwa tujuan pendidikan Islam mempunyai dua tujuan. Pertama, tujuan keagamaan, maksudnya beramal untuk akhirat, sehingga ia menemui Tuhannya dan telah menunaikan hak-hak Allah yang diwajibkan ke atasnya. Kedua, tujuan ilmiah yang bersifat keduniaan, yaitu apa yang diungkapkan oleh pendidikan modern dengan tujuan kemanfaatan atau persiapan untuk hidup (Yulius, 1994). Demikian pula Abdullah Fayad menyatakan bahwa pendidikan Islam mengarah pada dua tujuan. Pertama, persiapan untuk hidup akhirat. Kedua, membentuk perorangan dengan ilmu pengetahuan dan keterampilan untuk menunjang kesuksesan hidup di dunia. Semua rumusan tujuan yang dikemukakan di atas sesuai dengan nilai-nilai Islam.

Selanjutnya al-Gazali berpendapat bahwa tujuan pendidikan Islam yang paling utama ialah beribadah dan taqarrub kepada Allah SWT dari kesempurnaan insani yang tujuannya kebahagiaan dunia dan akhirat. Selain dari pandangan yang dikemukakan oleh al-Gazali tentang tujuan pendidikan Islam. Al-Gazali merumuskan tujuan umum pendidikan Islam kedalam lima pokok: 1) Membentuk akhlak yang mulia, 2) Persiapan untuk dunia dan akhirat, 3) Persiapan untuk mencari rezki dan pemeliharaan segi-segi pemanfaatannya. Keterpaduan antara agama dan ilmu akan dapat membawa manusia kepada kesempurnaan., 4) Menumbuhkan ruh ilmiah para pelajar dan memenuhi keinginan untuk mengetahui serta memiliki untuk suatu profesi tertentu sehingga ia mudah mencari rezki.

Dari beberapa arah tujuan pendidikan Islam, dapat disimpulkan bahwa tujuan pendidikan Islam adalah

1. Mendidik dan mengembangkan potensi anak agar mampu menjadi pemimpin di dunia dan melaksanakan tugasnya secara Amanah untuk kesejahteraan rakyatnya

2. Menyadarkan dalam jiwa anak-anak bahwa tujuan hidup ini adalah untuk beribadah kepada Allah SWT dengan cara penanamkan jiwa keislaman dalam setiap kegiatan dengan keyakinan bahwa semua milik Allah dan akan kembali ke Allah

3. Mendidik anak agar berakhlakul karimah, sehingga memiliki Atitude yang baik dan kepekaan social yang tinggi

4. Membentuk potensi anak sehingga memiliki tiga kecerdasan secara sempurna sebagai bekal didunia dan di akherat yaitu Intelektual Quotient (IQ), Emosional Quotient (EQ), dan Spiritual Quotient (SQ).

\section{Peluang dan Tantangan Pendikan Islam di Era Revolusi Industri 4.0}

Revolusi industry 4.0 merupakan konsep yang pertama kali diperkenalkan oleh ekonom asala Jerman, Profesor Klaus Scwab dalam bukunya yang bertajuk "The Fourth Industrial Revolution". Kaus mengungkapkan empat tahap revolusi industry yang setiap tahapannya dapat mengubah hidup dan cara kerja manusia. Revolusi industry 4.0 merupakan tahap terakhir dalam konsep ini setelah tahapan pada abad ke-18, ke-20, dan awal 1970. Saat ini kita telah memasuki fase keempat yang sering disebut dengan revolusi industry 4.0.

Pernahkan terbayangkan bagaimana majunya teknologi sepuluh tahun kedepan? Kehidupan ini akan terbiasa dengan robotrobot dan mesin-mesin, penggunaan kecerdasan buatan (artificial intelligence), nanotegnology, biotechnology, 3-D printing, 
The Internet of Things, Energy Storage, dan Quantum Computing. Perkembangan industry 4.0 menjadi tantangan bagi dunia pendidikan Islam. Para guru dituntut untuk mengikuti perkembangan. Ada beberapa tantangan revolus industry 4.0 di bidang pendidikan Islam, diantaranya:

Pertama, pergeseran cara mengajar dari tatap muka, bertemu diruang kelas menjadi pertemuan di ruang di dunia maya (Internet). Hal ini tentunya bertentangan dengan hakekat mencari ilmu atau belajar yaitu mencari keberkahan dari Allah dengan bertemu sang guru. Bagaimana jika di pondok pesantren mengaji namun tidak bertatap muka. Ilmu bisa didapat namun akhlak belajar, adab belajar, tauladan guru nya tidak bisa didapat secara maskimal. Tidak adanya relasi antara guru dan murid ini berdampak jelas terhadap degadrasi nilai-nilai Islam yang luhur. Dahulu guru dijadikan sebagai central of knowlegde, namun sekarang siapapun dapat mencari ilmu pengetahuan dari berbagai sumber digital yang bertebaran. Orang akan berfikir segala praktis dalam mencari jalan pintas dalam mencari ilmu tanpa berfikir bahwa belajar itu tidak hanya transfer knowledge tapi juga transfer nilai-nilai luhur. Sistem pendidikan ODL (online distance learning) yang dipromosikan oleh revolusi industry 4.0 tidak sejalan dengan nilai Islam. Padahal dalam relasi guru-murid terdapat nilai spriritual tinggi yang dinamakan konsep barokatologi, (faham keberkahan), dan suhbatu ustadzin (menghormati pengajar).

Kedua, Pendidikan Islam sangat memperhatikan keotentikan suatu ilmu dengan tujuan untuk memelihara dan mewariskan ilmu tersebut. Keotentikan dunia virtual diragunakan reliabelitasnya dan kredibilitasnya, karena tidak ada sanad dan riwayat yang jelas, karena hanya berdasarkan e-book, file, dan sebagainya. Ketiga, peran guru sebagai mu'allim (pengajar), mudabbir (pembimbing), mudarris (pendidik) tidak bisa digantikan oleh hal lain berupa tegnologi dalam dunia maya. Maka dari itu peran guru sangat penting dala sistem pendidikan. Keberhasila suatu pendidikan sangat tergantung pada persiapan guru dalam mendidik anak muridnya. Tidak hanya sekedar mentranffer ilmu pengetahuan, namun juga membangun kekuatan pendidikan karakter. Adapun mengenai perkembangan teknologi yang semakin maju memang tak dapat dihindari. Agama Islam juga syarat akan perkembangan (agama islam peka zaman). Namun perlu difahami bahwa Agama Islam adalah tujuan sedangka tegnologi adalah sarana. Yang terpentinga dalah bagaimana manusia menggunakan sarana itu, yaitu mampu mempermudah, merubah lebik baik, atau sebaliknya mempersulit dan merusak. Maka pendidikan islam harus mampu menjadi tiang yang mampu untuk menopang struktur kehidupan manusia dizaman modern ini dan mampu merekontruksi bangunan mental yang terkikis oleh perkembangan tegnologi.

\section{Peran Bahasa Arab dalam Studi Islam di Era Revolusi Industri 4.0}

Pendidikan Islam baik berbentuk formal maupun informal mengajarkan tentang ilmu-ilmu keislaman. Dalam bidang formal berbentuk sekolah-sekolah sedangkan informal berbentuk kajian-kajian, halaqah, pertemuan-pertemuan maupun pondokpondok pesantren. Tujuan pendidikan Islam adalah mengarahkan dan menggali potensi guna memiliki bekal secara intelektual, emosional, maupun spiritual agar mampu mebentuk kepribadian yang Kaffah (sempurna) berdasarkan al-Quran dan Hadist agar mampu menjalani kehidupan di dunia dan memiliki bekal ke akherat kelak.

Al-Quran dan Hadist serta ilmu-ilmu keislaman didalamnya tertulis dalam bahasa Arab, maka dari itu bahasa Arab menjadi "The Way" bagi umat Islam untuk mempelajarinya. Seluruh umat Islam tanpa terkecuali harus memahami bahasa Arab sebagai pintu masuk untuk mempelajari ajaran Islam. Bagi kalangan ilmuan mempelajari bahasa Arab menjadi hal yang urgen. Dalam kajian-kajian literature pendidikan Islam karangan ulama terdahulu semuanya berbahasa Arab., Hal ini menjadi problem dasar dan menyulitkan bagi para pembelajar untuk mengkajinya. Jalan satusatunya adalah memahami bahasa Arab terlebih dahulu. Berpijak dari sini 
pembelajaran bahasa Arab menjadi "Urgen" disebabkan:

1) Bahwa al-Quran dan Hadist sebagai sumber utama ajaran Islam ditulis dengan bahasa Arab.

2) Kitab-kitab karya ulama terdahulu yang mempengaruhi alur pemikiran dan pandangan umat Islam terutama di bidang Akidah, hadist, fiqih, tafsir, filsafat, tasawwuf ditulis dalam bahasa Arab.

3) Tugas dan karya ilmiah menjadi berkualitas jika mengambil rujukan langsung dari buku aslinya, yang mana buku asli tersebut kebanyakan berbahasa Arab, 4) Tuntutan akademik yang mengharuskan pembelajar atau mahasiswa mengkaji dan membaca buku-buku ilmiah berbahasa Arab, 5) Tuntutan zaman milenial yang menitik beratkan pada pengkajian pemikiranpemikiran ulama-ulama klasik yang kemudian di tarik ke dalam pemikiran pendidikan islam masa depan.

Dalam pendidikan Islam peranan tersebut adalah sebagai berikut: Pertama, Bahasa Arab memiliki "Role" yang utama yaitu sebagai bahasa Wahyu. Dalam Aquran surat Zukhruf ayat 2, Allah menjelaskan bahwa al-Quran turun dengan bahasa Arab, yang artinya:

"Sesungguhnya kami menurunkan alQuran berbahasa Arab agar kalian memahaminya".

Kedua, peran bahasa Arab sebagai alat komunikasi umat muslim kepada Allah SWT. Dalam prakteknya, ritual dan ibadah kepada Allah menggunakan bahasa Arab seperti doa-doa yang harus dibaca atau disebut pada shalat, dzikir dan sebagainya. Sholat sebagai bentuk medium manusia berkomunikasi langsung dengan Allah yang mana seluruh bacaan-bacaan di dalamnya memakai bahasa Arab. Jadi bahasa Arab dipelajari untuk memahami bacaan-bacaan tersebut agar tidak salah dalam memahami teksnya maupun beserta maknanya.

Ketiga, bahasa Arab merupakan salah satu bahasa Internasional. Peranan bahasa Arab sangat penting di dunia internasional baik dalam bentuk kegiatan formal maupun informal. Dalam kegiatan formal bahasa Arab di pelajari di sekolah-sekolah dan Universitas-universitas Islam di seluruh pelosok dunia. Di Negara-negara barat, Bahasa Arab menjadi bagian kurikulum utama, contohnya: di Leipziq Jerman bahasa Arab sudah menjadi kajian dan penelitian, begitu pula di Oxford University dan Harvard University. Di sektor informal bahasa Arab sudah menyebar dan menjadi bahasa komunikasi orang-orang yang tinggal disuatu Negara sebagai alat diplomasi dalam bidang perdagangan, politik dan sosial kemasyarakatan.

Empat, Bahasa Arab dijadikan alat untuk sebuah penelitian dan proyek besar kaum Orientalis untuk mengkaji islam dan kebudayaan di Negara-negara Timur. Penelitian-penelitian tersebut kemudian dikodifikasikan dalam buku, kamus, dan sebagainya yang bertujuan untuk mengintegrasikan kebudayaan Islam dan kebudaan barat. Contohnya adalah Kamus Munjid yang dikarang oleh seorang Orientalis bernama Louis Bin Naqula Dhahir Alma'luf (1867-1946) yang lahir di kota Zahlah Libanon. Ia adalah salah seorang pastur dan penganut kristiani, ia memulai studi lanjutannya sekolah fakultas kristen di Beirut. Contoh lain yaitu seorang orientalis yang bernama Fhilip K. Hitti (1886 - 1978) lahir di Shimlan Suriah Utsmaniyah (sekarang Lebanon). Dia merupakan seorang orientalis dan Islamolog ternama, yang memperkenalkan sejarah kebudayaan Arab ke Amerika berhasil mengarang buku the History of Arabic. Generasi muslim harus mengikuti perkembangan ini, agar generasi muslim tidak ketinggalan karya dalam peradaban islam.

Orintalis Barat mengakui bahwa bahasa Arab memberikan cakupan makna yang lebih luas dalam penulisan dan penafsiran ayat-ayat Al-Quran yang memungkinkan dibanding dengan bahasa Inggris. Pada waktu dulu, sekretarissekertaris kerajaan yang bukan orang Arab merupakan sebuah kebanggaan ketika dihadapkan bersama sekertaris orang Arab yang profisional berbahasa Arab. Pada zaman Khulafaurrasyidin hal ini sering 
dialami oleh mereka terlebih-lebih dimasa khalifah Umar bin Khattab berlanjut sampai masa keemasan Islam pada Dinasti Abbasiyah. Hal ini menjadikan mereka termotivasi untuk mempelajari tata bahasa Arab agar terhindar dari kekacauan tata bahasa atau kaidah bahasa ketika mereka menulis.

Bangsa Arab dalam sejarahnya berbaur dengan bangsa bukan Islam. Hal ini dikarenakan perkembangan inspansi kerajaan Islam serta perkembangan agama Islam ke berbagai penjuru. Bangsa Arab berbaur dengan bangsa Romawi, Paris, Eropa. Penuturan bahasa Arab mulai bercampur baur dengan bahasa-bahasa daerah penaklukan mereka. oleh karena itu khalifah Ali Bin Ali Thalib sangat khawatir bahasa Arab akan terlepas dari struktural bahasa semula atau bahasa ibunya. Diantara Faktor lain yang menjadikan bahasa arab penting karena bahasa Arab merupakan bahasa dunia yang diputuskan oleh PBB. Pembelajaran bahasa Arab di Indonesia saat ini telah mengalami perkembangan. Perkembangan bahasa Arab, seiring dengan perkembangan pendidikan Islam di pondokpondok pesantren. Seiring dengan perkembangan revolusi industry 4.0, maka pembelajaran bahasa Arab harus di revitalisasi pada semua bidang, yaitu kurikulum, materi, metodologi pembelajaran, arah tujuan pembelajaran.

Tabel. 1

Arah Perubahan Pembelajaran Bahasa Arab

Era Revolusi Industri 4.0

\begin{tabular}{|l|lr|}
\hline Arah tujuan & Arah rajuan \\
pembelajaran & pembelajaran bahasa \\
bahasa Arab & Arab di arahkan \\
& dengan pengembangan \\
& kompetensi siswa yaitu \\
& sofl skill dan hard skill \\
& baik pada jenjang \\
& sekolah tingkat dasar, \\
& menengah, atau \\
& lanjutan rarta \\
& perguruan tinggi \\
\hline Kurikulum & Kurikulum bahasa \\
& Arab disesuaikan \\
\hline
\end{tabular}

\begin{tabular}{|c|c|}
\hline & $\begin{array}{l}\text { dengan arah dan tujuan } \\
\text { pembelajaran abad } 21 \\
\text { yang memuat scientific } \\
\text { approach, rekonstruksi } \\
\text { karakter dan } r \text { skil } \\
\text { otentik pada ranah } \\
\text { sekolah, dan KKNI } \\
\text { pada ranah perguruan } \\
\text { tinggi }\end{array}$ \\
\hline Materi & $\begin{array}{l}\text { Desain materi di } \\
\text { arahkan } \\
\text { fungsionalitasnya dan } \\
\text { aplikasinya }\end{array}$ \\
\hline $\begin{array}{l}\text { Metodologi } \\
\text { Pembelajaran }\end{array}$ & \begin{tabular}{lr}
\multicolumn{2}{l}{ Metodologi diarahkan } \\
dan digeser & dari \\
tradisionalisme & \\
metodoogi & menuju \\
modernisasi & \\
metodologi, & seperti: \\
metode & terjemah, \\
metode & qawaid, \\
metode & ceramah \\
digeser ke & metode- \\
metode yang & mampu \\
mengaktifkan & kelas, \\
dan & membangun \\
kreatifitas & siswa \\
seperti & diskusi, \\
praktek, demonstrasi, \\
problem rem & based \\
learning, cooperative \\
learning, & quantum \\
teaching, & aktif \\
learning, & discovery \\
learning, brain based \\
learning dsb
\end{tabular} \\
\hline $\begin{array}{l}\text { Media } \\
\text { Pembelajaran } \\
\text { bahasa Arab }\end{array}$ & 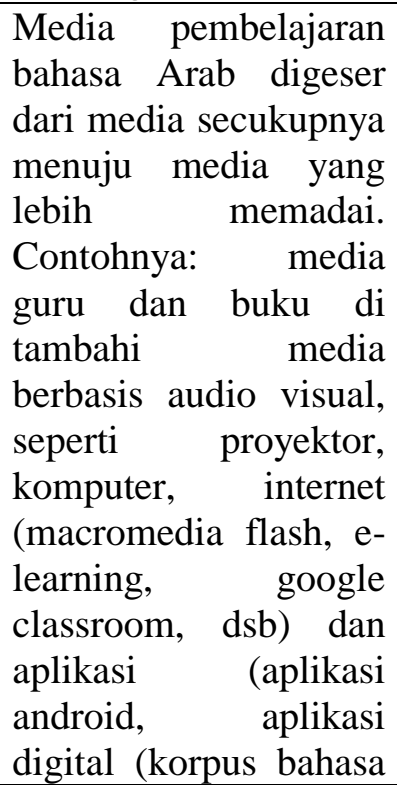 \\
\hline
\end{tabular}




\begin{tabular}{|c|c|}
\hline & $\begin{array}{l}\text { arab, kamus internet, } \\
\text { dsb). }\end{array}$ \\
\hline $\begin{array}{l}\text { Tenanga } \\
\text { Pendidik }\end{array}$ & $\begin{array}{l}\text { Mengupdate skill } \\
\text { Pendidik, } \\
\text { profesionalisme } \\
\text { keilmuan, kualifikasi } \\
\text { akademik yang linear, } \\
\text { kompetensi social dan } \\
\text { kepribadian yang baik } \\
\text { dan benar. }\end{array}$ \\
\hline $\begin{array}{l}\text { Evaluasi } \\
\text { Pembelajaran }\end{array}$ & $\begin{array}{l}\text { Evaluasi diarahlan } \\
\text { kepada tiga ranah yaitu } \\
\text { afektif, kognitif, dan } \\
\text { psikomotorik. Evaluasi } \\
\text { digeser dari based } \\
\text { pencil test (ujian tulis) } \\
\text { menuju otentik test } \\
\text { (produk, portofolio, } \\
\text { penilaian diri, jurnal, } \\
\text { penilaian kepribadian } \\
\text { dsb). }\end{array}$ \\
\hline $\begin{array}{l}\text { Pengembangan } \\
\text { Lembaga } \\
\text { Pendidikan }\end{array}$ & $\begin{array}{l}\text { Lembaga pendidikan } \\
\text { berbasis terpadu dan } \\
\text { bilingualisme } \\
\text { mengajarkan bahasa } \\
\text { Arab sebagai bahasa } \\
\text { Aktif selain sebagai } \\
\text { bahasa Pasif. }\end{array}$ \\
\hline
\end{tabular}

Pada Prinsipnya, belajar Bahasa Arab di Era revolusi industri 4.0 adalah Belajar Bahasa dengan semaksimal mungkin memanfaatkan teknologi informasi dan komunikasi sebagai sumber dan medium utama belajar bahasa Arab, misalnya internet. Strategi dalam belajar bahasa Arab di era millenial yaitu dengan sistem one day one sentence, dan one day one story. Bacalah berita-berita aktual dalam bahasa Arab melalui surat kabar digital atau elektronik, misalnya al-Ahrom, al-Jazera, dan lain-lain. Dari bacaan ini Anda akan mendapatkan istilah-istilah dan ungkapan baru yang sesuai dengan perkembangan zaman now. Belajarlah melalui Youtube Arab, carilah lagu -lagu Arab Fusha khususnya dari Youtube, bernyanyilah dan bergembiralah, dengan itu anda belajar pengucapan dan mufrodat (kosa kata) baru.

Berhubungan dengan revolusi Industri 4.0 tentunya dalam pengembangan bahasa Arab dan pembelajarannya membutuhkan Arah tujuan yang signifikan terhadap kemampuan softskill dan hardskill pembelajar. Pembelajar harus dibekali berbagai materi bahasa Arab yang mampu mengantarkannya ke dunia kerja dan bahasa komunikasi dengan kalayak umum. Pembelajar harus mampu berkomunikasi dengan bahasa Arab baik fusha maupun Amiyah. Dalam bahasa Arab fusha, pembelajar dibekali dengan model bahasa Arab untuk acara resmi seperti susunan ungkapan-ungkapan MC, Moderator, dan pembaca berita Arab. Mahasiswa juga di bekali susunan ungkapan-ungkapan atau kalimat bahasa Arab untuk pidato dan ceramah keagamaan. Tidak cukup itu pula pembelajar harus dibekali dengan bahasa Arab komunikatif berkonten, misalnya percakapan sehari-hari baik di rumah, di toko, di sekolah, di masjid, di pasar, di bandara, di rumah sakit dsb.

Pembelajar juga harus mempunyai skill berbahasa Arab untuk Umroh, Haji, dan bahasa Arab dalam bidang diplomasi dan perpolitikan baik nasional maupun internasional. Dengan hal itu semua diharapakan pembelajar mempunyai skill untuk mampu menjadi apapun baik itu guru, diploma, penerjemah dsb. Model materi yang disampaikan juga harus dirasa menjadi mudah oleh pembelajar. Unsur-unsur bahasa Arab diajarkan menggunakan model terapan. Seperti nahwu terapan, dan sharat terapan. Pembelajar diharapkan memiliki kompetensi pula dalam bidang tulis menulis bahasa Arab yang baik. Contohnya: mengarang cerita (Insya), menulis artikel berbahasa Arab, Menulis surat berbahasa Arab. Kemudian pembelajar juga memiliki seni yang tiggi di bidang kaligrafi dan ornamen berbahasa Arab. Pembelajar juga diharapkan mampu mengembangkan bahasa Arabnya dalam role playing seperti puisi berbahasa Arab, peribahasa Arab, drama berbahasa Arab dsb.

$$
\text { Dalam bidang metodologi }
$$

pembelajaran, diharapkan guru mampu menyajikan metodologi yang menarik, efektif, dan efisien untuk semua ragam latar belakang pembelajar. Model-model pembelajaran inovatif harsu dikembangkan di era revolusi industri ini seperti model 
pembelajaran aktif learning, pembelajaran berbasis permainan bahasa Arab, Pembelajaran Sugestopedia dalam bahasa Arab, Quantum teaching dalam bahasa Arab, Brain based learning dalam bahasa Arab, pembelajaran bahasa Arab berbasis otak kanan dsb. Media pembelajaran juga harus berkembang, terutama media dalam bidang informasi dan tegnologi. Penggunaan media internet harus di lakukan oleh guru agar siswa mampu mengakses alamat-alamat yang berisi tentang kebahasaaraban. Youtube yang mampu memberikan contoh tentang pola-pola ungkapan bahasa Arab native. Penggunaaan media yang lagi di gemari oleh dosen-dosen saat ini seperti google classroom dan e-learning. Semua ini menjawab tantangan pembelajaran bahasa Arab dalam revolusi Industri 4.0. Apabila pembelajaran bahasa Arab berkembang maka secara otomatis pendidikan Islam akan berkembang pula, karena bahasa Arab merupakan "pintu" masuknya hal-hal yang berhubungan dengan keilmuan dan pengetahuan dalam pendidikan Islam.

\section{SIMPULAN}

Bahasa Arab menjadi "Urgen" dalam pendidikan Islam disebabkan hal-hal berikut:

1. Sumber ajaran Islam yaitu Alquran dan Hadist ditulis dengan bahasa Arab

2. Kitab-kitab karya ulama terdahulu yang mempengaruhi alur pemikiran umat Islam terutama di bidang Akidah, hadist, fiqh, tafsir, filsafat, dan tasawwuf ditulis dalam bahasa Arab.

3. Tugas dan karya ilmiah menjadi berkualitas jika mengambil rujukan langsung dari buku aslinya, yang mana buku asli tersebut kebanyakan berbahasa Arab,

4. Tuntutan akademik yang mengharuskan pembelajar atau mahasiswa mengkaji dan membaca buku-buku ilmiah berbahasa Arab,

5. Tuntutan zaman milenial yang menitik beratkan pada pengkajian pemikiranpemikiran ulama-ulama klasik yang kemudian di tarik ke dalam pemikiran pendidikan islam masa depan

\section{DAFTAR PUSTAKA}

Atha Ibn Khalil, 2000, Taisir Wushul Ila alWushul: Dirasat Fi Usul Al-Figh, Cet. ke-3, Darul Ummah, Beirut.

Ahmad Izzan, 2009, Metodologi Pembelajaran Bahasa Arab, Cet. ke-3, Humaniora, Bandung.

Ahmad Naquib al-Attas, 1998, Kapita Selekta Pendidikan Islam, Bandung, Pustaka Setia.

As-Syaibany, 2005, Ilmu Pendidikan Dalam Perspektif Islam, Bandung, PT. Remaja Rosdakarya.

Ahmad Tafsir, 2012, Ilmu Pendidikan Islam, Bandung, Rosda Karya.

Miller G Davis J, \& Russell A, Information Revolution, Using The Information Evolution Hamzah B. Uno \& Nina Lamatenggo, 2010, Teknologi Komunikasi \& Informasi Pembelajaran, Jakarta, Bumi Aksara.; 2006, Model to Grow Your Business, New York: John Wiley \& Son

Hasbi Ash Shiddieqy, 1975, Falsafah Hukum Islam, Jakarta, Bulan Bintang.

M. Akawi Jad, 1987, Al-Muhasah alYaumiyyah bi al-Lugah al-Arabiyyah, Mesir, Daar al-Ma'arif.

M. Fadhil al-Jamaly, dalam Bukhari Umar, 2011, Ilmu Pendidikan Islam, PT. Bumi Aksara, Jakarta.

Ramayulius, 1994, Ilmu Pendidikan Islam, Jakarta, Kalam Mulia.

Musthafa al-Ghalayaini, 2005, Jami ad-Durus al-Arabiyah, Dar al-Hadits al-Qahirah.

Y. Hady, (2018, 04 29), Tantangan Revolusi Industri 4.0, Retrieved from yuswohady.com:http://www.yuswoha dy.com/2018/04/29/tantanganrevolusi-industri-4-0/. 